\title{
Physical activity and health promotion strategies among physiotherapists in Rwanda
}

\author{
*Frantz JM, Ngambare R
}

Department of Physiotherapy, University of the Western Cape, Bellville

\begin{abstract}
Background: Physical inactivity has become a global health concern and is among the 10 leading causes of death and disability. Physiotherapists are in a position to combat inactivity and effectively promote physical activity to their clients. Objectives: To establish the relationship between physical activity levels of physiotherapists and their physical activity promotion strategies.

Methods: A sequential mixed method design was used by means of a self-administered questionnaire $(\mathrm{n}=92)$ and a focus group discussion comprising of 10 purposively selected physiotherapists. Descriptive statistics were employed to summarize demographic information. Inferential statistics was used to test the associations between different categorical variables $(\mathrm{p}<0.05)$. Tape recorded interviews were transcribed. Thematic analysis was then done.

Results: The findings revealed that $64 \%$ of the participants were physically active both within the work and recreation domains and $65 \%$ of the participants had good physical activity promoting practices. Discussing physical activity and giving out information regarding physical activity were most common methods used in promotion of physical activity. Policies on physical activity, cultural influence, and nature of work, time management as well as the environment were the barriers highlighted.

Conclusion: Although physiotherapists experience barriers to promoting physical activity, they have good physical activity promoting practices.

Key words: physical inactivity, chronic diseases of lifestyle, health promotion strategies, physiotherapy, Rwanda African Health Sciences 2013; 13(1): 17 - 23 http://dx.doi.org/10.4314/ahs.v13i1.3
\end{abstract}

\section{Introduction}

The World Health Organization has described chronic diseases of lifestyle as the leading cause of mortality in the world, representing $60 \%$ of all deaths ${ }^{1}$. The burden of mortality, morbidity and disability attributable to chronic diseases is currently greatest and is continually growing in the developing countries. It was estimated that by 2020 , chronic diseases associated with diet and lifestyle in Sub-Saharan Africa will constitute almost $50 \%$ of the burden of disease $^{2,3}$. Literature has highlighted that lack of physical activity, unhealthy diet, tobacco and alcohol use contribute in a large part to chronic diseases of lifestyle ${ }^{4}$. Physical inactivity has been identified as a serious global public health problem which is associated with numerous preventable diseases and has been classified as the fourth leading risk factor

\begin{tabular}{|l|}
\hline *Corresponding author: \\
Prof José M Frantz \\
University of the Western Cape \\
Private Bag x17 \\
Bellville \\
7530 \\
Tel: 27219592542 \\
Email: jfrantz@uwc.ac.za \\
\hline
\end{tabular}

African Health Sciences Vol 13 Issue 1 March 2013 for global mortality ${ }^{5}$. The World Health Organization estimates that globally the prevalence of physical inactivity among adults is $17 \%$, ranging from $11 \%$ to $24 \%$ across different regions of the world ${ }^{1}$.

In order to combat this health concern linked to physical inactivity there is a need for health promotion interventions that focus on single factors such as physical inactivity. It has been argued that primary healthcare professionals such as physiotherapists are ideally placed to promote physical activity within local communities to combat the impact of chronic diseases of lifestyle. "Many health professionals including physiotherapists take health promotion as an integral part of their role" as health promotion and health education are currently one of the core competencies expected from the physiotherapy profession ${ }^{6}$. It is further indicated that physiotherapists should prioritize and organize their efforts based on their skills and knowledge of physical activity and guided by community preventive evidence based recommendations for promotion of physical activity to advocate for the inclusion of physical activity policies in various settings ${ }^{7}$. Within the primary health 
care setting, health professionals are considered an important part of a wider public health drive to encourage more people to become physically active. If physiotherapists should advocate and address health promoting physical activity then they could promote health holistically.

The conceptualization of health promotion in physiotherapy is different from other fields of health promotion which emphasize empowerment as the central concept of health promotion but instead health education is the most emphasized health promotion strategy in physiotherapy ${ }^{8}$. Researchers have indicated that "health education and health promotion activities are a fundamental requirement for all health professionals. These two paradigms are closely related but are not interdependent"'. Worldwide, the World Health Organization is advocating for physical activity as a preventive measure to chronic diseases of lifestyle. While a growing body of literature supports the effectiveness of physical activity interventions delivered in the primary care setting, few studies have evaluated efforts concerning the use of physical activity as a health promoting strategy by physiotherapists. The aim of the study was to establish the physical activity levels of physiotherapists in Rwanda and their physical activity health promotion practices.

\section{Methods}

The study employed a sequential mixed method design and was conducted in referral and district hospitals of Rwanda. The quantitative method was a descriptive cross section survey and the qualitative component incorporated a focus group discussion. In Rwanda there are 160 registered physiotherapists of whom 142 registered physiotherapists worked in public and private hospitals, clinics and institutions of higher learning. For the current study physiotherapists working in the referral and district hospitals $(n=104)$ were targeted for the quantitative aspect of the study. In addition, ten physiotherapists from the study sample were purposively selected to participate in the focus group discussions based on the outcomes of the Physical Activity Exit Interview (PAEI) questionnaire completed by participants in the quantitative component.

Data from the physiotherapists were collected by means of self-administered questionnaires which consisted of 3 sections. The first section requested for demographic information and information on physical activity based on the reliable and valid World Health Organization Steps framework instrument for non-communicable diseases risk factors ${ }^{10,11}$. The WHO STEPS surveillance instrument has been used in various African countries ${ }^{12,13}$. Another section of the questionnaire was the valid and reliable Physical Activity Exit Interview (PAEI) which measured the content of physical activity promoting practices by physiotherapists ${ }^{14}$. In the focus group discussion an interview guide with probes for discussions was developed based on the aim of the study and literature.

Ethical clearance was obtained from the ethics committee at UWC (10/8/20) and permission was obtained from the Ministry of Health, the Rwanda national ethical committee, and the directors of the hospitals at which the study was conducted. Written informed consent was obtained from all participants and they were informed that participation was voluntary. Permission was also obtained from the participants in the focus group discussion to use a tape recorder to capture audio data during the focus groups discussion and a confidentially form was signed by all participants.

Data for the quantitative study was analysed using the Statistical Package for Social Science (SPSS) version 18.0. Descriptive statistics was employed to summarize the demographic data and a continuous indicator of Metabolic Equivalent Task (MET) was used to estimate the mean physical activity levels of the sample, the total time spent in physical activity in a typical week, the number of days as well as the intensity of physical activity. Inferential statistics using the chi-square was employed to compare association between physical activity levels and other variables like physical activity promoting strategies $(\mathrm{p}<0.05)$. For the qualitative data, analysis included, transcribing interviews, typing field notes, sorting and arranging data, making sense and overall meaning of information and coding information into categories. The narrative data was subjected to the process of interpretation and analysis.

\section{Results}

All physiotherapists practicing in referral and district hospital were invited to participate in the study yielding a total of 104 physiotherapists. Of the 104 questionnaires distributed, a total of 92 physiotherapists voluntarily participated in the study giving a response rate of $88.5 \%$. Among the participants, males accounted for $70 \%(n=64)$ and females $30 \%(n=28)$. The participants' age ranged 
from 26- 60 years, with a mean age of 32.49 years $(\mathrm{SD}=6.56)$. Participants had work experience of ranging from between 1 year to 34 years, with a mean working experience of 1.62 years $(\mathrm{SD}=1.03)$. Most of the participants' highest education level was a diploma $(70 \%)$, followed by a BSc degree $(21 \%)$ and a Masters degree $(9 \%)$.

\section{Physical activity levels in relation to physical activity domains}

According to reported physical activity levels, 28\% were classified as sedentary, 33\% moderately active and 39\% vigorously active. Participants' physical activity levels were assessed with regard to the different physical activity domains such as: work, transport and recreational activities. The highest mean MET- minutes/week (2685.9) was recorded at work, followed by the recreational physical activity domain (table 1).

Table 1: Mean MET-minutes/week in physical activity domain in relation to the demographic characteristic

\begin{tabular}{|c|c|c|c|}
\hline \multirow[t]{2}{*}{ Characteristics } & \multicolumn{3}{|c|}{ Mean MET minutes/week } \\
\hline & Work & Recreation & Transport \\
\hline \multicolumn{4}{|l|}{ Gender } \\
\hline Male & $2695.9 *$ & $1102.5^{*}$ & $554.4^{* *}$ \\
\hline Female & $2685.7^{*}$ & $765.0^{*}$ & $617.2^{*}$ \\
\hline \multicolumn{4}{|l|}{ Marital status } \\
\hline Single & $2024.2^{*}$ & $1078.0^{*}$ & $569.0 * *$ \\
\hline Married & $2747.1 *$ & $1159.0 *$ & $539.1 * *$ \\
\hline \multicolumn{4}{|c|}{ Level of education } \\
\hline Diploma & $2376.0^{*}$ & $826.8^{*}$ & $753.0^{*}$ \\
\hline BSc degree & $2436.0^{*}$ & $1248.0^{*}$ & $724.7 *$ \\
\hline Masters & $2588.0^{*}$ & $1748.5^{*}$ & $477.2^{*}$ \\
\hline
\end{tabular}

\section{Physical activity promoting practices}

Physical activity promoting practices were analyzed using the Physical Activity Exit Interview Questionnaire and the study found that $65 \%$ had high physical activity promoting practices, $32 \%$ had moderate physical activity promoting practices and $3 \%$ had poor physical activity promoting practices. No statistically significant association was found between physical activity levels and physical activity promoting practices $(p>0.05)$. Participants below the age of 35 years had higher physical activity promoting practices (51\%) than any other age group and males $(46 \%)$ had high physical activity promoting practices compared to the females $(20 \%)$. The most common form of health promotion strategies used by physiotherapists included discussing physical activity participation with their clients $(98 \%)$, rather than the use of written material (9\%).
Barriers to physical activity health promoting practices

Participants in the focus group discussion consisted of 5 participants who had good physical activity health promoting strategies and 5 who had poor physical activity health promoting strategies. In the focus group discussions with the participants, four themes emerged as the barriers to promoting physical activity among clients with six categories and eleven subcategories. The themes, categories and subcategories are presented in Table 2 and supported with relevant quotations. 
Table 2: Themes and categories developed from qualitative data analysis

\begin{tabular}{|c|c|c|c|c|}
\hline Themes & Categories & Subcategories & Participants experiences & \begin{tabular}{|l|} 
Quotes \\
\end{tabular} \\
\hline \multirow[t]{4}{*}{$\begin{array}{l}\text { Policy on } \\
\text { physical activity }\end{array}$} & \multirow[t]{2}{*}{$\begin{array}{l}\text { Government policy } \\
\text { on physical activity }\end{array}$} & Funding & $\begin{array}{l}\text { Participants felt that governmen } \\
\text { had not effectively budgeted for } \\
\text { the role out of the physical } \\
\text { activity policy to institutions }\end{array}$ & $\begin{array}{l}\text { "The government policy is there } \\
\text { but it is not well defined to give } \\
\text { good directions such that } \\
\text { institutions know their }\end{array}$ \\
\hline & & Infrastructure & $\begin{array}{l}\text { The policy is not clear on the } \\
\text { development of facilities linked } \\
\text { to promoting physical activity. }\end{array}$ & $\begin{array}{l}\text { esponsibility in encouraging their } \\
\text { employees in engaging in } \\
\text { physical activity and sports and } \\
\text { also give a universal day for all } \\
\text { institutions to allow their } \\
\text { employees to participate in } \\
\text { physical activity." (P7). } \\
\text { "Although the policy is there, } \\
\text { the government does not allocate } \\
\text { a budget for physical activity to } \\
\text { institutions and this makes it } \\
\text { a problem for institutions to buy } \\
\text { equipment for sports and promote } \\
\text { physical activity." (P8) }\end{array}$ \\
\hline & \multirow[t]{2}{*}{$\begin{array}{l}\text { Institutional } \\
\text { Policy on Physical } \\
\text { activity }\end{array}$} & $\begin{array}{l}\text { Implementation } \\
\text { Plan }\end{array}$ & $\begin{array}{l}\text { Policies exist but there is no } \\
\text { clear guidelines for } \\
\text { implementation as to when } \\
\text { and how }\end{array}$ & \multirow{2}{*}{$\begin{array}{l}\text { "Due to lack of policy from our } \\
\text { institution to promote phyiscal } \\
\text { activity, this may stop the } \\
\text { institution from improving the } \\
\text { staff's knowledge on physical } \\
\text { activity for example there is a } \\
\text { lack of books or articles on } \\
\text { physical activity in the library.» } \\
\text { (P6) }\end{array}$} \\
\hline & & $\begin{array}{l}\text { Inconsistent } \\
\text { support }\end{array}$ & $\begin{array}{l}\text { Support to implement effective } \\
\text { physical activity strategies at the } \\
\text { workplace tended to vary from } \\
\text { institution to institution }\end{array}$ & \\
\hline \multirow[t]{2}{*}{$\begin{array}{l}\text { Time manage } \\
\text { ment }\end{array}$} & Lack of time & $\begin{array}{l}\text { Long working } \\
\text { hours }\end{array}$ & $\begin{array}{l}\text { The government policy to work } \\
\text { nine hours a day tend to deprive } \\
\text { people time to engage in } \\
\text { physical activity }\end{array}$ & $\begin{array}{l}\text { "Time may be a factor because } \\
\text { we can't get time during working } \\
\text { hours due to the big number of } \\
\text { appointments we give to our } \\
\text { clients. It's very hard for us to } \\
\text { make a follow up and we can't go } \\
\text { out to their homes." (P2) }\end{array}$ \\
\hline & & \begin{tabular}{|l|} 
Additional \\
Responsibilities
\end{tabular} & $\begin{array}{l}\text { Due to the high cost of living } \\
\text { in Rwanda people tend to take } \\
\text { different jobs for supplement } \\
\text { their income or further their } \\
\text { education in hope of a better } \\
\text { pay. }\end{array}$ & $\begin{array}{l}\text { Due to other additional } \\
\text { responsibilities we have, for } \\
\text { example there are some staff } \\
\text { among us who have opted to } \\
\text { continue their further studies so } \\
\text { when they are not working they go } \\
\text { go for studies, so time is a } \\
\text { barrier." (P4) }\end{array}$ \\
\hline $\begin{array}{l}\text { Cultural influence } \\
\text { on physical activ- } \\
\text { ity }\end{array}$ & e Cultural Restriction $\$$ & \$ Gender & $\begin{array}{l}\text { Boys were groomed to be } \\
\text { protectors of families while girl } \\
\text { were groomed to be mothers } \\
\text { and family wives hence not allo- } \\
\text { wed in physical activity while } \\
\text { men were trained to be warriors } \\
\text { therefore allowed to do physical } \\
\text { activity }\end{array}$ & $\begin{array}{l}\text { "The Rwandan Culture plays a } \\
\text { s big role in influencing physical } \\
\text { activity. It prevents some groups } \\
\text { of people from participating in } \\
\text { physical activity for example } \\
\text { women were not allowed to } \\
\text { participate in physical activity, } \\
\text { they were only allowed to do } \\
\text { simple tasks like cooking and } \\
\text { other tasks that did not require } \\
\text { use of energy."... because of how } \\
\text { people dressed some time back, } \\
\text { women were required to dress in } \\
\text { long dresses. This would hinder or } \\
\text { discourage doing physical } \\
\text { activity.." }\end{array}$ \\
\hline
\end{tabular}




\begin{tabular}{|c|c|c|c|c|}
\hline Themes & Categories & Subcategories & s Participants experiences & Quotes \\
\hline & & \begin{tabular}{|c|} 
Cultural image \\
\end{tabular} & $\begin{array}{l}\text { Culture view women as } \\
\text { veak so they were given less } \\
\text { strenuous activities that did } \\
\text { hot involve a lot of energy } \\
\text { expenditure }\end{array}$ & \\
\hline & & Dress Code & $\begin{array}{l}\text { Women in the Rwandan } \\
\text { culture are mothers into the } \\
\text { sfociety therefore they are } \\
\text { obliged to have a special } \\
\text { dress code cover their body } \\
\text { f which it prevents them } \\
\text { from doing physical activit- } \\
\text { ies and sports }\end{array}$ & \\
\hline & & Cultural beliefs & $\begin{array}{l}\text { The primarily responsibilit- } \\
\text { ies of women was to give } \\
\text { birth and look after childre } \\
\text { and their husbands }\end{array}$ & $\begin{array}{l}\text { "Women were prevented from doing } \\
\text { beavy work their only role was to give } \\
\text { birth, look after the children and } \\
\text { husbands at home and prepare food } \\
\text { and the rest of work was done by men } \\
\text { and children." (P3) }\end{array}$ \\
\hline $\begin{array}{l}\text { Environmental } \\
\text { influence on } \\
\text { physical } \\
\text { activity }\end{array}$ & $\begin{array}{l}\text { Physical factors } \\
\text { (infrastructure) }\end{array}$ & $\begin{array}{l}\text { Distance to } \\
\text { facilities }\end{array}$ & $\begin{array}{l}\text { Participants felt that lack of } \\
\text { facilities in their surroundin } \\
\text { communities contributed to } \\
\text { ack of physical activity parti } \\
\text { cipation }\end{array}$ & $\begin{array}{l}\text { "For me the sports centre is a long } \\
\text { distance away from where I stay, } \\
\text { so I have to walk or pay for } \\
\text { i- transport, therefore financial means } \\
\text { also limits me from going there." (P6) }\end{array}$ \\
\hline
\end{tabular}

\section{Discussion}

Physical activity has been globally recognized to have the solution and prevention of increasing chronic diseases of lifestyle. Increase in physical inactivity is evidence that the world population is engaging less in physical activity ${ }^{5}$. Health professionals, especially physiotherapists are in a better position to promote physical activity among their clients ${ }^{15}$. Although physiotherapists may have the knowledge, the promotion of physical activity as a health promotion strategy is influenced by various factors such as personal practices, the cultural beliefs of the population factors and policy.

In the current study, physiotherapists in Rwanda were equally represented in all categories of physical activity level participation, with them being most active whilst at work. Compared to other health professionals in South Africa, research found that most nurses working in public hospitals were considered to be sedentary ${ }^{16}$. The difference between physiotherapists and the other sample population may be due to their knowledge of physical activity acquired during their training when still in school compared to other populations. Physiotherapists are perceived as experts in the promotion of physical activity. It is in this regard that their clients/patients and other health professionals respect their advice concerning health matters. This puts physiotherapists in the best position to advocate and influence their clients' participation in physical activity ${ }^{15}$. In the current study discussing physical activity and the use of written materials on physical activity were the strategies used in promoting physical activity to clients/ patients. These strategies are similar to those commonly used in New South Wales, Australia where it was reported that physiotherapists used some of these strategies to promote physical activity ${ }^{17}$. Other health professions like doctors ${ }^{14}$, did not use written materials or give written exercise plans to their patients. It was also revealed that it was easier for dieticians ${ }^{18}$ to discuss physical activity than giving written material since it's time consuming and costly.

What is important from the current study is the emphasis on the cultural influence on physical activity participation as indicated by the following quote "The Rwandan Culture plays a big role in influencing physical activity. It prevents some groups of people from participating in physical activity for example women were not allowed to participate in physical activity". This lends us to understand the role of cultural competence as a core skill among health professionals. However a study 
conducted by Murrock and Madigan ${ }^{19}$ helps us to focus on culture in a way that promotes physical activity. In most cultures traditional dances and positive lifestyle activities are encouraged thus it can be used to promote physical activity and researchers are encouraged to explore the positive aspects of culture on physical activity ${ }^{19}$. In addition, to improve cultural beliefs as mentioned by the participants in the current study, research highlighted that for national policies and plans on physical activity to be implemented and be successful, they should be socially inclusive and participatory ${ }^{3}$. Therefore cultural ties and influence should be considered.

Finally, if health promotion strategies are to be plausible, it should be guided by policy as is the case in Rwanda. However, challenges exist and if these challenges are not addressed effectively the policy will not serve its purpose. It has been highlighted that for national policy to be implemented effectively, all stakeholders should comply and develop institutional policies that work hand in hand with the national policy and have effective collaboration in all physical activity programs ${ }^{20}$. Therefore responsibility should be defined at every level so that activities should not overlap.

\section{Conclusion}

Based on the findings of the current study, it is evident that physically active physiotherapists are well positioned to incorporate health promotion strategies that can encourage patients to participate in physical activity. However, the successful implementation of these health promotion strategies related to physical activity is still influenced by barriers such as government policy, cultural influences, environmental influences and time constraints experienced by the practitioner.

\section{Implications for practice}

It is thus important for physiotherapists and other health professionals to be empowered about intervention strategies within the limited resources we are faced with and governments should streamline the policy on physical activity for better promotion of physical activity.

\section{References}

1. World Health Organization (2008a).Chronic diseases. Retrieved on October 17, 2010 from www.who.int/topics/chronic_diseases/en/.
2. Sobngwi E, Mauvais-Jarvis F, Vexiau P, Mbanya JC, Gautier JF. Diabetes in Africans: Epidemiology and clinical specificities. Diabetes Metabolism Research and Reviews, 2001; 25(6): 629- 634

3. World Health Organization.(2005). Review of best practice in interventions to promote physical activity in developing countries.

Retrieved on April 23, 2011 from www.who.int/dietphysicalactivity/ bestpractice

4. Yach D, Hawkes C, Gould, CL, Hofman KJ. The Global burden of chronic diseases: overcoming impediments to prevention and control. Journal of the American Medical Association, 2004; 291(21): 2616-2622.

5. World Health Organization.(2010). Global Recommendations on Physical activity for Health. Retrieved on March 2, 2011 from www.who.int/dietphysicalactivity/ factsheet_recommendations/en/index.html

6. Whitehead D. Evaluating health promotion: a model for nursing practice. Journal of Advanced Nursing, 2003; 41 (5): 490-498.

7. Simon P, Gonzalez E, Ginsburg D, Abrams J, Fielding J. Physical activity promotion. A local and state health department perspective.Preventive Medicine, 2009; 49 (4): 297-298.

8. Perreault K. Linking health promotion with physiotherapy low back pain. A review. Journal of Rehabilitation Medicine, 2008; 40(6): 401-409.

9. Whitehead D. Health promotion and health education: advancing the concepts. Journal of Advanced Nursing, 2004; 45: 159-168.

10. World Health Organization.(2003).The WHO STEPwise approach. Retrieved on April 16, 2010 from http://www.afro.who.int/cdp/ documents/steps_tools

11. Armstrong T, Bull F. Development of the World Health Organization Global Physical Activity Questionnaire.Journal of Public Health, 2006; 14(2): 66-70.

12. Frantz, J. The views of learners regarding a school based health education programme. African Journal of Physical Health, Education Recreation and Dance, 2009; 15(3): 409-416.

13. Tawa, N. (2009). The prevalence of risk factors for non-communicable diseases among people living in Mombasa, Kenya.Unpublished Master's thesis. 
Physiotherapy department University of Western Cape.

14. Sciamanna CN, Goldstein MG, Marcus BH, Lawrence K, Pinto BM. Accuracy of recall of exercise counselling among primary care patients.Preventive Medicine, 2004; 39: 1063 1067.

15. Gosselink R. Physiotherapists should be leaders in waging the war against inactivity induced chronic diseases. New Zealand Journal of Physiotherapy 2008; 36(2), 78.

16. Naidoo R., Coopoo Y. The health and fitness profiles of nurses in Kwa-Zulu Natal.Curationis, Research Magazine 2007; 30, 1 8.

17. Shirley D, van der Ploeg HP, Bauman AE. Physical activity promotion in the physical therapy setting: perspectives from practitioners and students. Journal of Physical Therapy. 2010; 90(9): 1311-1322.

18. McKenna J, Henderson L, Baic S. A survey to assess physical activity promotion by Registered Dietitians.Journal of Human Nutrition Dietitian, 2004; 17:63-69.

19. Murrock CJ, Madigan E. Self-efficacy and social support as mediators between culturally Specific dance and lifestyle physical activity. Research and Theory for Nursing Practice: An International Journal, 2008; 22(3):192-204.

20. World Health Organization. (2007). A guide for population-based approaches to increasing level of physical activity: implementation of the WHO Global strategy on diet, physical activity and health. Retrieved on March 28, 2011 from www.who.int/dietphysicalactivity/ physical-activity-promotion 